\title{
Assessment of nursing students in clinical practice - An intervention study of a modified process
}

\author{
Rita Baumgartner ${ }^{* 1}$, Cecilia Häckter Ståhl ${ }^{1}$, Katri Manninen ${ }^{1,2}$, Ann-Marie Rydholm Hedman ${ }^{1}$ \\ ${ }^{1}$ The Swedish Red Cross University College, Department of Health and Nursing, Stockholm, Sweden \\ ${ }^{2}$ Department of Infectious Diseases, Karolinska University Hospital, Stockholm, Sweden
}

Received: May 14, 2017

Accepted: June 26, 2017

Online Published: July 9, 2017

DOI: $10.5430 /$ jnep.v7n11p111

URL: https://doi.org/10.5430/jnep.v7n11p111

\begin{abstract}
Objective: To evaluate an intervention of a modified assessment process for nursing students in clinical practice and how this process was experienced by the nursing students and their supervisors.

Methods: An intervention study with a descriptive approach. The data collection was conducted in two phases with a survey and follow-up group interviews. Participants were second-year nursing students and their nursing supervisors. Descriptive statistics were used for the quantitative data (survey) and qualitative content analysis for the qualitative data (tape-record and transcribed interviews). Mixed method was used to integrate all data.

Findings: The survey response rate was $65 \%(n=41$ students) and 100\% ( $\mathrm{n}=9$ supervisors). Students and supervisors found the assessment tool applicable for the assessment process. Assessment through dialogue and Supportive learning environment, describe how the modified assessment process was experienced.

Conclusions and implication for clinical practice: It is important that the supervisors understand the learning goals and assessment criteria and how to use the assessment tool. Clear structures based on learning goals and assessment criteria as well as their own strategies to reach their goals benefit student learning. Strategies need to be developed to facilitate the assessment process when the teachers from the university have a consulative role. The new assessment tool and changing the university teachers' involvement can be seen as a form of professional development of the supervisors' group as they take greater responsibility in conducting the assessment of nursing students in clinical practice.
\end{abstract}

Key Words: Assessment, Nursing competence, Learning goals, Mixed-methods, Intervention

\section{BACKGROUND}

The World Health Organization, Europe has prepared a document to support the implementation of principles for the training of general nurses. ${ }^{[1]}$ This implementation of training should include a minimum of three years of theoretical and clinical training, should take place in hospitals or other health care bodies and include supervision by other qualified nurses to help support nursing students. A nursing supervisor's role is to evaluate the nursing student's knowledge and skills required within nursing care (Article 31 of 2005/36/EC). WHO
Europe requires that nursing students learn to organise, dispense and evaluate comprehensive nursing care within the health institute and/or community and that training should be assessed under the supervision of qualified nursing staff within a clinical environment that is appropriate and where knowledge and skills can be adequately assessed (ibid).

Nursing is a dynamic profession that is under constant change due to the increasingly ageing population and the ongoing advancement of technology within healthcare organisations, ${ }^{[2]}$

\footnotetext{
*Correspondence: Rita Baumgartner; Email: baur@rkh.se; Address: Department of Health and Nursing, The Swedish Red Cross University College, Box 1059. 14121 Huddinge, Sweden.
} 
thus affecting the changes within the areas of nursing competence. Three main multidimensional competence areas are identified for nursing students in Europe: nursing skills, knowledge, attitudes and values (ibid).

In order to assess the nursing students' areas of competence during clinical practice measurable assessment tools and assessment processes are required to ensure that the quality of nursing competences is judged accurately and holistically. Studies have shown a need to assess the entire list of competencies to match the reality of clinical practice. ${ }^{[3]}$ Assessing clinical competence to meet specific national guidelines is complex and equally important is an instrument to help enable the supervisor to make sound judgments. ${ }^{[4]}$ Not only is there a need for an assessment tool to help facilitate sound judgement, it is also necessary to assess effectively and objectively within clinical practice since the assessment process often lacks consistency due to the involvement of several participants. ${ }^{[5]}$

Research has shown that various assessment tools have different areas of focus to assess students' competence during clinical practice. Some universities have assessment tools that highlight the course-specific learning goals measuring whether intended learning outcomes have been reached or not. ${ }^{[6,7]}$ Other studies have explored the assessment of competence within clinical practice, however, the focus has been on the intuitive aspects of assessing, in particular psychomotor abilities ${ }^{[8]}$ rather than the multidimensional nature of competence such as nursing skills, knowledge and attitudes and values. ${ }^{[2]}$ Another study on the development and validation of new tools measuring self-reported professional competence found that only a few tools for the assessment of nursing student competence tested the psychometric areas of competence. ${ }^{[9]}$ This raises the question of how clinical competencies are defined and the difficulty in assessing them to meet the needs of their specific national guidelines. ${ }^{[10]}$ In response to the problem of how clinical competencies are defined, a break down of nursing competencies can help to validate the assessment process. ${ }^{[11]}$ A break down gives rise to clear aims and learning outcomes thus stimulating a positive assessment process and learning environment. ${ }^{[4,12]}$ While it is important to have clear assessment objectives and learning outcomes to facilitate the assessment of nursing competencies within clinical practice, it is equally important that nursing students acknowledge their own learning needs. Each nursing student has individual learning needs and styles ${ }^{[5]}$ it is therefore important to harvest student awareness of learning strategies concerning why and how they learn. ${ }^{[13]}$ Equally important is the supervisor's role in creating learning opportunities so that the nursing student is more aware of what needs and skill level is required. ${ }^{[12]}$ Nursing students should take charge of their own individual learning needs by writing personal strategies ${ }^{[11]}$ and be accountable for their own learning needs. ${ }^{[8]}$ Enabling nursing students to write personal learning strategies helps promote the development of meaningful learning. ${ }^{[14]}$ Consequently, the development of a clinical assessment tool that sets goals for achievement and provides possibilities for specific feedback on learning is important within the assessment process. ${ }^{[15]}$

Maintaining quality assessment of nursing students' professional competence, learning strategies and adequate feedback during clinical practice is still a challenge. A small aggregate of facts is available regarding suitable assessment tools and the assessment process in clinical practice during higher nursing education to assess nursing competence. Therefore, this study's aim was to evaluate an intervention of a modified assessment process for nursing students in clinical practice and how this process was experienced by nursing students and their supervisors.

\section{METHOD AND MATERIAL}

The current study comprised data from a survey and group interviews. The analysis process was carried out in several steps, and the final steps revealed themes with subthemes.

\subsection{Design}

This study applied a descriptive mixed methods design which was used to clarify and amplify the meaning of the quantified descriptions of the students' and supervisors' perspectives of the assessment process. A combination method can be used to expand the scope of a study as the researchers seek to capture method-linked dimensions of a target phenomenon. ${ }^{[16]}$ Students and supervisors with similar backgrounds and knowledge of the phenomenon, but with different roles, participated in a survey and a group interview. A purposeful sampling technique was used to recruit the participants of the study.

\subsection{Study setting}

The setting for the study was three wards at the Department of Infectious Diseases at Karolinska University Hospital in Sweden. The hospital is a teaching hospital for various healthcare profession students and the department trains, among others, nursing students at different levels. The patients are admitted to the ward from the hospital's emergency ward or from the outpatient clinic at the department. They are informed about the organisation and assured that although the students act independently, the supervisors are responsible for both patient safety and for the students' learning. The term supervisor was used for the nursing supervisor and clinical teacher with student responsibility, and nursing students were referred to 
as students in this study.

One of the three wards is a clinical education ward with a special focus on training students in clinical practice. The ward has eight beds in which fifteen students simultaneously do their clinical practice. Four nurses, a nursing assistant, a clinical lecturer and a physician serve as supervisors and are responsible for the assessment process. The pedagogical framework is based on Mezirow's ${ }^{[17]}$ theory of transformative learning and consists of patient-centeredness, peer learning and a supervisory team. This means that the students take care of their own patients, individually or in pairs, as independently as possible. The students are allowed to act as nurses; they plan, perform and follow up the nursing care of their patients. The supervisors work as a team challenging and supporting the students.

The two other wards are ordinary wards in which four students simultaniously do their clinical practice. The number of beds on the wards vary from 18 to 23 beds. The students take care of their own patients with support from the nurses on the ward who serve as supervisors. One nursing supervisor works as a clinical teacher and is responsible for planning and organising the clinical practice on the ward. Each student has a supervisor who is mainly responsible for the assessment process. The pedagogical framework is based on peer learning which means that students at the same level work and learn collaboratively with support from the supervisors. The students help each other to acquire and train theoretical and practical knowledge and skills during the clinical placement. ${ }^{[18]}$ This framework also involves students working as independently as possible, training for their future profession on the wards.

\subsection{The interventions}

The intervention consisted of introducing a modified assessment process including a new assessment tool and changes regarding the teacher's role in the assessment process.

\subsubsection{A new assessment tool}

A validated assessment form was previously used in the evaluation of clinical practice in the assessment discussion dialogue. This form provided information to support the course-specific learning goals. ${ }^{[19]}$ Specific learning goals were included in the curriculum, and these were evaluated and assessed. Since this is a requirement in higher education, initiated reflections on the development of a new assessment tool were required. Development of the new tool started with a literature review of current assessment tools. ${ }^{[6,7,9]}$ The new assessment tool included course specific learning goals with assessment criteria. To support students' self-reflection and implementation of the learning goals the assessment tool included a question relating to the students' own strategies to reach their learning goals (see Figure 1).

\subsubsection{Teachers involvement in assessment discussions}

The assessment dialogue in clinical practice previously consisted of a three-party discussion including students, supervisors, and teachers from the university. The intervention meant that the teacher's role was changed and became consultative. However, a teacher was always present when a student was falling short of achieving the learning goals. This meant that the assessment dialogue was usually held with a supervisor and a student.

\subsection{Data collection}

Data were collected through a survey and with follow-up group interviews during two periods (see Table 1).

\subsubsection{Survey and follow-up}

The survey consisted of closed and open-ended questions as well as demographic variables.

Questions concerning learning goals, assessments criteria and assessment processes were measured using closed-ended response alternatives on a Likert scale of 1-4, which included the following statements: to a very high degree, to a high degree, to some degree, not at all. The four open-ended questions asked students and their supervisors to describe their own experiences (see Table 2).

The questionnaire was distributed to the participants by giving a paper questionnaire to the students in a classroom and personally to the supervisors on the wards. Demographic variables were collected through the survey. The survey took place after the students' half time in clinical placement (after four weeks). For the nursing supervisors this took place after the students had finished their clinical placement (after eight weeks).

Follow-up group interviews were created to obtain a deeper understanding of the students' and the supervisors' experiences of the assessment process. The semi-structured interview questions were constructed from the answers in the survey (see Table 3).

All the follow-up group interviews occurred after the students had finished their clinical placements (after eight weeks). They were audio recorded and lasted about 50 minutes each. The interviewer (students/supervisors RB and supervisors CHS) encouraged the participants by asking follow-up and probing questions. The supervisors expressed different aspects of the assessment tool during the assessment process (face validity). 


\begin{tabular}{|c|c|}
\hline Learning goals & Assessment criteria \\
\hline $\begin{array}{l}\text { Apply the nursing process based on person-centred care and } \\
\text { documentation of patient's records }\end{array}$ & $\begin{array}{l}\text { - be able to apply person-centred care and to understand and } \\
\text { explain the significance of information obtained through patient } \\
\text { assessments by the patient, other health professionals, } \\
\text { caregivers, relatives and patient records. } \\
\text {-independently implement nursing interventions such as } \\
\text { drawing up care plans based on nursing diagnosis for short- } \\
\text { and/or long-term goals and strategies. } \\
\text {-follow up nursing interventions and documentation of activity } \\
\text { plans/standard care plans. } \\
\text {-be able to document patients' history, current status, nursing } \\
\text { diagnosis, goals, actions, and summary of care plans using } \\
\text { correct language and writing. }\end{array}$ \\
\hline \multicolumn{2}{|c|}{ Half-way assessment } \\
\hline \multicolumn{2}{|c|}{$\begin{array}{l}\text { On way towards achieving the learning goals } \\
\text { Flaws or partial flaws towards achieving the learning goals }\end{array}$} \\
\hline \multicolumn{2}{|l|}{ Feedback from the nursing supervisor and or clinical teacher } \\
\hline \multicolumn{2}{|c|}{$\begin{array}{l}\text { Students own learning strategies towards achieving the learning goals (to be handed in to the nursing supervisor before the half-way } \\
\text { assessment) }\end{array}$} \\
\hline \multicolumn{2}{|c|}{ Final assessment } \\
\hline \multirow{2}{*}{\multicolumn{2}{|c|}{$\begin{array}{l}\text { Has achieved all the learning goals } \\
\text { Has not achieved all the learning goals }\end{array}$}} \\
\hline & \\
\hline \multicolumn{2}{|l|}{ Feedback from the nursing supervisor and or clinical teacher } \\
\hline
\end{tabular}

Figure 1. Example of the assessment tool based on learning goals and assessment criteria during clinical practice

Table 1. An overview of data collection and analysis process

\begin{tabular}{|c|c|c|c|c|}
\hline \multirow[b]{2}{*}{$\begin{array}{l}\text { Participants } \\
\text { Nursing students and } \\
\text { supervisors }\end{array}$} & \multicolumn{2}{|c|}{ Data collection periods } & \multirow{2}{*}{$\begin{array}{l}\text { Survey } \\
\text { Closed-ended and linked } \\
\text { open-ended questions } \\
\mathrm{n}=50\end{array}$} & \multirow[b]{2}{*}{$\begin{array}{l}\text { Follow-up group interviews } \\
\text { Semi-structured interviews } \\
\mathbf{n}=\mathbf{1 5}\end{array}$} \\
\hline & $\begin{array}{l}2015 \\
\text { The autumn } \\
\text { semester }\end{array}$ & $\begin{array}{l}2016 \\
\text { The spring } \\
\text { semester }\end{array}$ & & \\
\hline The clinical education ward & $\mathrm{X}$ & $\mathrm{X}$ & $\mathrm{X}$ & $\mathrm{X}$ \\
\hline The two ordinary wards & - & $\mathrm{X}$ & $\mathrm{X}$ & $\mathrm{X}$ \\
\hline Type of analyses & & & Descriptive statistics & Qualitative content analysis \\
\hline \multicolumn{5}{|c|}{ Quantitative and qualitative data were merged and described in two themes with subthemes } \\
\hline
\end{tabular}


Table 2. Presentation of the open-ended questions in the survey

\begin{tabular}{lc}
\hline Open-ended questions to the students & Open-ended questions to the supervisors \\
\hline $\begin{array}{l}\text { Tell me about your experiences of the assessment dialogue } \\
\text { Describe the assessment criteria usability and provide examples }\end{array}$ \\
The assessment tools application and any suggestions for improvement \\
$\begin{array}{ll}\text { Give examples of your experience of the situation (being alone with } & \text { Give examples of your experience of the situation (being alone with the } \\
\text { the supervisor and without the teacher), both positive and negative } & \text { student and without the teacher), both positive and negative }\end{array}$ \\
\hline
\end{tabular}

Table 3. Examples of questions for the follow-up interviews

Group interview question areas for the student and supervisor groups were as follows:
Experiences of the assessment interview without a teacher present and the difference between the half time and final assessment interview.
Experiences of the learning goals in relation to the clinical placement period.
Experiences of the students' individual learning strategies to achieve the required learning goals.
Example of the first question with follow-up questions:
Describe your experiences of the assessment interview.
Give an example of a situation you thought went well.
Give an example of a situation you thought did not go so well.
How did your experience differ between the half time and final assessment interview?
How did you experience not having a teacher present during the assessment interview?

\subsubsection{Participants and response rate}

The students were recruited from the second year of a threeyear nursing programme during an eight weeks clinical course entitled "Medical Surgical Nursing Care". The students who did their clinical practice at the clinical education ward and at the two ordinary wards at the Department of Infectious Diseases were invited to participate in the study. In addition, nursing supervisors who worked at the three wards during the selected periods were invited to participate in the study.

As shown in Table 1, 50 students and supervisors answered the survey and 15 participated in the follow up interviews. In total, 63 students were invited to participate. The students survey response rate was $65 \%(n=41)$. Twenty-one respondents during the autumn of 2015 and twenty respondents during the spring of 2016. Thirty-three of respondents were women $(80 \%)$, six were men $(15 \%)$ and two were not defined (5\%). Thirty-two of the students were 20 to 30 years of age (78\%) and nine were 31 years of age and above (22\%). There were twenty-two non-responses (35\%), seven during the autumn of 2015 and fifteen during the spring of 2016. Their sex and age are unknown.

The supervisors' survey response rate was $100 \%(n=9)$. The four participating supervisors from the clinical education ward were all women, aged 27-57 years. The five clinical teachers/nursing supervisors from the other two wards were also women, aged 26-36 years. They all had previous experience of acting as supervisors.

In total, four follow-up group interviews, two with students and two with clinical teachers/nursing supervisors were con- ducted with some of the participants from the survey.

\subsection{Data analysis}

Demographic variables and survey question response rates were summarised using descriptive statistics (percentage and median).

The answers from the open-ended questions in the survey and the text from the follow-up interviews were transcribed verbatim (RB, CHS). The text amounted to a total of 10,398 words from the student interviews and 11,088 words from the supervisors. Thereafter, an analysis was undertaken using qualitative content analysis. ${ }^{[20,21]}$ The first step in analysing data was the coding and categorisation process which was guided by the aim of the study and from the perspectives of the students and the supervisors. During the first step the authors worked in pairs; two authors analysed the student interviews and two authors analysed the supervisor interviews. Each pair of authors read through their respective interviews several times in their entirety and coded and categorised the data to clarify the manifest content. There were initially 47 codes and 8 categories from the student interviews. There were initially 27 codes and 11 categories from the supervisor interviews.

In the second step of the analysis process all the authors met to discuss the manifest content, i.e. the codes and categories from their respective interviews. After integrating the manifest content, a further interpretation was carried out by all the authors together (see Table 4). The aim of this interpretation was to reach the latent content of the data, which means a deeper understanding of how the modified assessment process was experienced by the students and supervisors during 
the clinical practice. In the final step, the quantitative and qualitative descriptions were merged into findings that clarify and amplify the meaning of the students' and supervisors' experience of the assessment process. Verbatim quotations were presented to illustrate the findings.

Table 4. An example of levels of the coding process

\begin{tabular}{|c|c|c|c|c|}
\hline Perspective & Meaning units & Categories & Subtheme & Theme \\
\hline \multirow{2}{*}{$\begin{array}{l}\text { From follow-up } \\
\text { interviews with } \\
\text { students }\end{array}$} & $\begin{array}{l}\text { Experience important to understand the meaning of } \\
\text { the grading criteria. Abstract for novices. }\end{array}$ & Students own experiences & Key persons & $\begin{array}{l}\text { Assessment } \\
\text { through dialogue }\end{array}$ \\
\hline & $\begin{array}{l}\text { Supervisors had a requirement that I knew how I } \\
\text { would reach the goals }\end{array}$ & Supervisors support & & \\
\hline $\begin{array}{l}\text { From follow-up } \\
\text { interviews with } \\
\text { supervisors }\end{array}$ & $\begin{array}{l}\text { She (the teacher) was always good at asking other } \\
\text { questions that went deeper into the learning goals. I } \\
\text { felt that I couldn't quite do that }\end{array}$ & $\begin{array}{l}\text { Supervisor's view of a } \\
\text { teacher present }\end{array}$ & & \\
\hline
\end{tabular}

\subsection{Ethical considerations}

Approval for the project was granted by the Research Board/Head of Department of Care and Nursing, at the Red Cross University College and the Head of Department of Infectious Diseases Karolinska University Hospital. The study follows the ethical rules laid down by the Belmont Report. ${ }^{[22]}$ This implied that oral and written information about the study's aim, voluntary participation, confidentiality and the right to conceal information or withdraw at any time was given to the students and supervisors prior the data collection. The information was given prior to participation in the clinical practice. The interviews were conducted at venues on the premises within convenient access for the students (a classroom). As for the supervisors, the interviews were conducted in a conference room connected to the ward in the hospital. The interviewers (RB, CHS) did not take part in the assessment process during the data collection.

\section{FINDINGS}

The findings below integrate data generated from the survey and the group interviews. Two main themes, Assessment through dialogue and Supportive learning environment, describe how the modified assessment process was experienced (see Figure 2). The findings support the view that assessment through dialogue involving key persons and an assessment tool, carried out in a supportive learning environment, are important aspects in experiencing the assessment process in clinical practice.

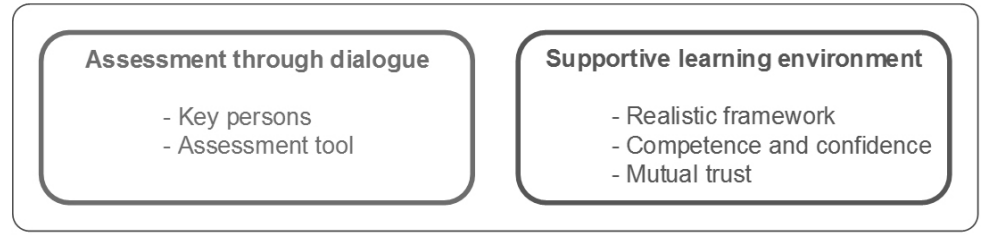

Figure 2. The themes and the sub-themes that describe how the modified assessment process was experienced by students and supervisors

\subsection{Assessment through dialogue}

The theme Assessment through dialogue has two sub-themes Key persons and Assessment tool and describes aspects concerning the dialogue in relation to the assessment process. The core elements for the dialogue are informed and attentively present key persons

As shown in Table 5, students and supervisors were positive to the assessment tool as they found the learning goals and the criteria comprehensible and applicable for the assessment process. All three questions in the survey were evaluated with a median of "to a very high degree". Furthermore, it was relaxing to have an assessment dialogue without a teacher present. The teacher from the university was perceived as an expert in the assessment process and that their mission was to engage in dialogue in difficult situations.

\subsubsection{Key persons}

The students stressed that well-informed students, supervisors and clinical teachers were the key persons for the students' assessment during the clinical placement. They stated that there was no need for a teacher from the university to be present during the dialogue except in situations when the supervisor lacked an understanding of the assessment procedure and the assessment tool. The students also emphasised the significance of having a clinical teacher helping them to 
understand the learning goals.

It was more relaxed, you had a good relationship with the clinical teacher, there was no need for the teacher who does not know me and my progress at all. Student interview

However, the students emphasised the importance of having a teacher present in situations when they felt uncomfortable about being alone with the nursing supervisor due to differing views on progress in relation to expectations. In the same way, it could help the student to have a teacher present to deal with a problem regarding a specific supervisor.

The supervisors stressed the need of support from a teacher in situations when a student was not achieving the learning goals or when there was an apparent risk of a student failing.

She (the teacher) was always good at asking other questions that go deeper in the learning goals. I felt that I couldn't quite do that. Supervisor interview

\subsubsection{The assessment tool}

Students and supervisors stressed the importance of both parties being well informed about the assessment tool and how to use it effectively. When the assessment tool was used correctly, it contributed to student development and a higher level of progress.

Having clear learning goals helped the students to think critically about their own progress and the supervisors to assess the students. Overall, it was expressed that the assessment tool helped to stimulate the students towards critical thinking about their own area(s) of development. The students emphasised that the learning goals for the clinical course should be formulated in relation to the clinical placement and education level and be well grounded in theory.

The assessment tool was experienced as an aid to opening up the dialogue and also to maintaining the focus. It emerged that the assessment dialogue was generally based on the learning goals and the assessment criteria. The students expressed that the assessment criteria were helpful in clarifying the learning goals and that they used the assessment criteria not only as a checklist, but also as guidelines to formulate their own strategies. The students communicated that writing their personal strategies clarified their own responsibility for learning and that they felt involved when their own learning strategies were used in the assessment dialogue. Using students' own learning strategies was on the other hand a challenge for some supervisors, as they did not fully understanding the purpose.

Published by Sciedu Press
Provide a little more information about the assessment tool, how to work in the best way. Student interview

The supervisors expressed that having comprehensible learning goals and criteria reduced the risk of misinterpretation. Learning goals not directly related to the clinical placement were more challenging to assess. The order of the learning goals in the tool helped maintain a logical structure during the assessment dialogue.

I think that the learning goals help me to find situations to discuss. Supervisor interview

The supervisors were positive about the opportunity to assess a student "on his/her way towards achieving the learning goals" as it was felt too definite to pass or fail a student during the half way assessment dialogue. This helped the supervisor and student to weigh in what areas of development needed to be focused on during the remaining placement period.

We went through each learning goal and strategy ... this made them (the students) feel much stronger. Comments such as "I can do that now" or "I can continue to develop that" helped them to see their progress ... It empowered the student. Supervisor survey

Face validity was related to the supervisors' view of how user friendly the assessment tool was. One suggestion was that the assessment tool could be more specific when describing the rationale behind students writing their personal strategies. The supervisors provided comments about the design of the assessment form in order to obtain a better overview concerning the learning goals. Furthermore, another sequencing of the learning goals and assessment criteria was suggested to obtain a better flow during the assessment discussion. All the supervisors pointed out some assessment criteria that were unclear and a couple of new assessment criteria relating to one of the learning goals were also suggested.

\subsection{Supportive learning environment}

The theme Supportive learning environment has three subthemes Realistic framework, Competence and confidence, and Mutual trust and they describe aspects concerning the learning environment in relation to the assessment process. The core elements for a constructive assessment process in clinical placement are a realistic environment with an explicit structure for supervision and competent supervisors resulting in students feeling entrusted. 


\subsubsection{Realistic frameworks}

The students expressed that the clinical placement needs to give them a realistic experience of clinical work and that the supervision should be structured in such a way that it also helped them to achieve the learning goals for the clinical course.

The students emphasised differences in supervision between the clinical education ward and the ordinary ward. Students who had a placement at the clinical education ward meant that there was an explicit plan for their learning, which included learning tools such as checklists and weekly goals. Furthermore, the students stated that the feedback they received from their nursing supervisors was well thought through and that they appreciated several supervisors' assessments on their development and progress. Another important aspect was continuity; having several but the same supervisors during the clinical placement.

The goals were on the whiteboard and you could see them every morning and we read them aloud and knew what we should focus on. Student interview

In contrast, the students on the ordinary ward did not experience a similar explicit plan for their learning. Furthermore, these students expressed having too many supervisors who did not know them or their progress during the clinical placement. Some of the supervisors lacked knowledge of how to help the students reach the learning goals during their clinical placement.

The clinical teacher held my half-time assessment... I did two shifts with her and my final assessment was held by two other nurses who I did one or two shifts ... They knew nothing about me and my progress. Student interview

Our intention was to have fewer supervisors, unfortunately there were too many involved with students. Obviously, it made it more difficult to get to know the individual students. Supervisor survey

\subsubsection{Competence and confidence}

Experience played an important part in just how confident the supervisors were when they were alone during the assessment dialogue. The supervisors experienced a sense of confidence when they became familiar with the learning goals as this enabled them to have a better understanding of what was expected. This helped them make demands on the students who were not quite reaching the learning goals.
Even the students emphasised the importance of both supervisors and students understanding how the assessment tool should be used to help clarify expectations for both parties.

... there should be more information for both supervisors and students on how the assessment tool should be used... like what is expected from the supervisors, and what is expected of me as a student. Student interview

The supervisors indicated that they lacked the confidence and experience to be alone and ask questions about the content of the learning goals at a deeper level. It was also particularly hard when students showed a lack of understanding regarding coming prepared to their assessment dialogue since they considered preparation to be time-consuming. This made it challenging for the supervisors to have a constructive dialogue. The supervisors expressed that the assessment dialogue was sometimes one-sided and strained, particularly when the students sat quietly and expected them to give examples and feedback, or when students were hesitant to contribute to the conversation for fear of failing.

I had one student in my group who did not say anything, she just sat there, and was really scared that I was going to fail her. She preferred that I talk and give examples instead of her. Supervisor interview

Some students felt a lack of development progress when they sensed that their supervisors were mostly occupied with their own profession and responsibility. Other students found it challenging to contribute to the assessment dialogue because they felt inadequate having an experienced supervisor.

We had a different outlook on things. It's hard when you have a supervisor that is skilled and does everything right. Looking back I think that we both should have worked a little bit more on our conversation together. Student interview

\subsubsection{Mutual trust}

The students stated that they experienced being alone with their supervisor as private and relaxed, that they had a sense of trust. They emphasised the need to be seen as individuals with varying needs. Feedback on the student's performance was perceived as essential for further progression. A sense of trust was perceived when the supervisors were well informed about the learning goals and the students' individual performance and progress; otherwise the feedback was not meaningful for the students. The students also welcomed the possibility to create a support plan if they did not meet the criteria for learning goals. 
I felt that they (the supervisors) kind of pushed us forward... it was a good routine they had. Student interview

Also for the supervisors it was important to be well informed about the students' performance and progress to be able to give them constructive feedback. The supervisors stated that they got information both from supervising themselves and from their colleagues. Being well informed constituted a sense of having a professional foundation for the supervisor. The supervisors stressed that when students were well pre- pared for the assessment, the dialogue was characterised by mutuality where both supervisors and students contributed with information relating to the learning goals. The dialogue included aspects of the students' strengths and weaknesses, which were reflected on and discussed.

I got the feeling that the student did not feel singled out but that we tried to identify what was not working out for this student. .. what we supervisors should do in a different way. Supervisor interview

Table 5. An overview of the number (n) and percentage (\%) of answers to the closed-ended questions in the survey. The study included 50 participants of which 41 were nursing students (NS) and 9 supervisors (S).

\begin{tabular}{|c|c|c|c|c|c|c|}
\hline \multirow[t]{2}{*}{$\begin{array}{l}\text { Closed-ended } \\
\text { questions/ } \\
\text { Response alternatives }\end{array}$} & \multicolumn{2}{|c|}{$\begin{array}{l}\text { The assessment dialogue was } \\
\text { based on the learning goals and } \\
\text { assessment criteria }\end{array}$} & \multicolumn{2}{|c|}{$\begin{array}{l}\text { The assessment criteria were } \\
\text { helpful in the assessment of the } \\
\text { student }\end{array}$} & \multicolumn{2}{|c|}{$\begin{array}{l}\text { Comfortable being alone with the } \\
\text { nursing supervisor/the student } \\
\text { during the assessment dialogue }\end{array}$} \\
\hline & NS n (\%) & S n (\%) & NS n (\%) & S n (\%) & NS n (\%) & S n (\%) \\
\hline To a very high degree & $30(73)$ & $7(78)$ & $28(68)$ & $8(89)$ & $24(59)$ & $2(22)$ \\
\hline To a high degree & $10(24)$ & $2(22)$ & $11(27)$ & $1(11)$ & $9(22)$ & $5(56)$ \\
\hline To some degree & - & - & - & - & - & $1(11)$ \\
\hline Not at all & - & - & - & - & - & - \\
\hline Not answered* & $1(2)$ & - & $2(5)$ & - & $8(19)$ & $1(11)$ \\
\hline Median & $\begin{array}{l}\text { To a very high } \\
\text { degree }\end{array}$ & $\begin{array}{l}\text { To a very high } \\
\text { degree }\end{array}$ & $\begin{array}{l}\text { To a very } \\
\text { high degree }\end{array}$ & $\begin{array}{l}\text { To a very high } \\
\text { degree }\end{array}$ & $\begin{array}{l}\text { To a very high } \\
\text { degree }\end{array}$ & $\begin{array}{l}\text { To a very high } \\
\text { degree }\end{array}$ \\
\hline
\end{tabular}

*Unknown reason for non-response

\section{Discussion}

In order to improve the assessment process during clinical practice in higher nurse education, we introduced an intervention consisting of a new assessment tool and a change in involvement from the university teachers in the assessment dialogue. This study evaluated how the modified assessment process was experienced by the students and their supervisors. However, the quantitative results were not tested for significance.

\subsection{Discussion of findings}

Although both students and supervisors were positive to the modified assessment process, the students were more comfortable with "being alone with the nursing supervisors/alone with students, without a teacher present", compared to the opinion expressed by the nursing supervisors. There is, however, a discrepancy in frequency of answers due to the fact that the non-response from the students was higher than that of the supervisors. On the other hand, the nursing supervisors evaluated the use of the learning goals and assessment criteria more highly during the assessment dialogue than was the case for the students.

\subsubsection{Facilitation or hindrance in assessment}

The study revealed that the assessment tool was considered comprehensible for both students and supervisors. The tool

Published by Sciedu Press was easy to fill in and was applicable to the level of learning during the clinical placement. By including expertise such as nursing supervisors and clinical teachers as well as nursing students in the study we gained insight into the tool's validity.

One weakness however when using the modified assessment tool was the supervisors' understanding of the learning goals and assessment criteria. Misinterpretation of the content, inability (lack of experience) to ask questions at a deeper level about the learning goals were apparent in some cases. This affirms the fact that assessment tool terminology should be written in a language that is comprehensible and should concentrate on relevant situations that can be measured during clinical practice ${ }^{[23,24]}$ otherwise this can create an obstacle to constructive assessment between a supervisor and student. ${ }^{[8,24]}$ Consequently, the importance of having assessment criteria related to the clinical practice supports a better understanding of what is expected of both the student and the supervisor. Having an understanding of the learning goals helps to increase confidence among nursing supervisors as studies show that a lack of understanding can make it more difficult to define one's role, which thereby results in a nursing supervisor not fully understanding what is required of the student. ${ }^{[25]}$

Implementing support such as training nursing supervisors in 
nursing curriculum in general and specifically the assessment process, learning goals and criteria and their requirements helps to reduce the barriers to effective supervision and facilitates that feedback to nursing students can be given in a correct and critical manner. ${ }^{[2,12]}$ This is in line with our findings that support the view that educational institutions should provide information on how to use the assessment tool, particularly how to be prepared for an assessment dialogue with respect to the learning goals and the assessment criteria.

The findings show that it was hard for the students to write their individual strategies but once written they were able to better understand the learning goals. When learning strategies are used correctly by the students and supervisors they help towards a better understanding of one's own responsibility for learning. In a review, Cadorin et al., ${ }^{[14]}$ found that the use of strategies stimulates student progress and helps the student to become more aware of their shortcomings. Accordingly, students need to practice writing their own learning strategies effectively and this should be implemented at an earlier stage in nursing education, hence also promoting a student-centred learning environment. The findings also highlight how learning goals and assessment criteria related to clinical practice helped in finding examples during the assessment discussion and thereby contributed towards a better dialogue between student and supervisor.

\subsubsection{Authenticity and trust}

The importance of a supportive learning environment turned out to be one of the main findings indicating that a clinical setting with an explicit framework for supervision and a strategic learning plan facilitates both for students to achieve the learning goals and for nursing supervisors to assess the students. Having clear aims and learning goals also stimulates a positive assessment process and learning environment ${ }^{[4,12]}$ and reduces the void between education and the work environment. Nevertheless, such clear definitions of learning goals should also match the reality of clinical practice. ${ }^{[26]} \mathrm{A}$ contributing factor in defining competencies in nursing practice is the application of structural frameworks. Structural frameworks such as individual learning plans, written reflections, reflections on progress and the summative assessment of individual competencies add to the facilitation of learning and assessment. ${ }^{[3]}$ Such frameworks also help to maintain a satisfactory learning environment and a common language between educational institutions and the clinical workplace thus strengthening the collaboration between these two institutions in the clinical learning environment. ${ }^{[27,28]}$ Clinical placement needs to be representative and give the students a realistic experience of clinical work. According to WHO Europe $^{[1]}$ it is recommended that nursing students should learn to organise, dispense and evaluate comprehensive nursing care. This supportive learning environment can be linked to the concept of authenticity that has been found to be essential for students' learning. ${ }^{[29]}$ Authenticity is experienced when students are provided with both challenges and support in an environment that is realistic with an explicit framework for supervision.

Our study shows that students wanted a teacher present during the assessment interview only when supervisors lacked understanding of the learning goals. Additional studies confirm that students value the insightful discussions of their teachers when they feel there is inadequate understanding of the learning goals on the part of their supervisors. ${ }^{[30]} \mathrm{Im}$ plementing support for the supervisor such as understanding nursing curriculum and its requirements helps to reduce the barriers to effective supervision and facilitates that feedback to nursing students can be given in a correct and critical manner. ${ }^{[2,12,30]}$

Trust is another important aspect of learning in a clinical context ${ }^{[31]}$ and a sense of trust between students and supervisors in the assessment process was found to be especially important in our study. The findings also show that students felt trust in supervisors if they had had ongoing contact and continuity regarding their supervision during the clinical placement. Supervisors seemed to strive towards creating a less formal atmosphere during the assessment interview when a teacher was not present. What implications this has for the assessment process has not been fully studied and is therefore highly relevant for further research.

\subsection{Methodological considerations}

This multiple study design consisted of both quantitative and qualitative data from purposive samples of students and supervisors involved in clinical practice.

When analysing those who withdraw from the survey, we could not find any systematic differences compared to the respondents. The proportion of male nursing students who responded to the survey was slightly lower, 15 percent, than in the nursing programme at the university in question. The number of male nursing students has been between 18 and 21 percent during the past five years, but in the country as a whole the proportion of male students was 12 to 14 percent in nursing programmes. ${ }^{[32]}$ Thus, there can be some gender bias in the present study.

In qualitative approaches, issues of credibility, transferability, dependability and confirmability are related to descriptions of the procedure of the study. ${ }^{[20,33]}$ A strength of this study is that the interviewers were teachers from the university with experience in the field of clinical practice and assessment of 
nursing students. This experience can facilitate communication during the interview situations. Furthermore, to ensure independence, none of those who carried out the interviews was involved in the assessment process with the included students. A limitation was the use of a semi-structured interview technique as these questions may be less reflective than open-ended questions. Therefore, we suggest open-ended questions in further research to achieve deeper understanding. Nevertheless, our findings indicate that the intervention of the assessment process was successful. However, the learning goals and assessment criteria need to be further developed according to educational needs.

A core question of credibility is transformation and the relationship between empirical data and described themes. ${ }^{[20]}$ One strength of this study was that the degree of concordance was substantial during the process of thematisation. Credibility refers to how trustworthy the results are through capturing the participants' perspective (ibid). To achieve credibility we tried to carefully describe the study context, the participants and the analysis process so that the findings of the study could be confirmed and transferable. It is our belief that similar patterns as shown in the present findings and conclusion are transferable to other contexts when assessing nursing students during clinical practice. Original quotes from the survey and interviews were provided to support the relevance of the themes with subthemes. ${ }^{[34]}$

This study used mixed-methods as its study design to gain a greater understanding of the research problem that of introducing a new assessment tool and studying the framework for the assessment process. ${ }^{[35]}$ This methodology requires rigorous procedures in the data collection of each method. Therefore, appropriate sample sizes for data analyses of quan- titative and qualitative data were ensured. However, the present findings should be viewed with caution since only a few participants were included in the survey and statistical significance has not been calculated. In further research, the recommendation is to include more participants to draw general conclusions from the evaluation.

\section{Conclusions}

It is of importance that the supervisors are aware of and understand the learning goals and assessment criteria and how to use the assessment tool. Students' learning can benefit from building up clear structures based on learning goals and assessment criteria as well as from their own strategies for reaching the goals. Strategies need to be developed to increase and facilitate the assessment process and the dialogue between students and supervisors when the teachers from the university have a consultative role in the assessment process.

\section{IMPLICATION FOR CLINICAL PRACTICE}

This intervention can be seen as a kind of professional development of the supervisor group as they take greater responsibility in conducting the assessment of nursing students in clinical practice.

\section{ACKNOWLEDGements}

We wish to acknowledge the help of all the informants in making this work possible. This study was supported by The Swedish Red Cross University College, Huddinge, Sweden and J \& G Strandbergs fund from Stiftelsen Röda Korshemmet.

\section{CONFlicts OF InTEREST Disclosure}

The authors declare that there is no conflict of interest.

\section{REFERENCES}

[1] Keighley T. European Union standards for nursing and midwifery: Information for accession countries. Copenhagen. 2009; WHO Regional Office for Europe.

[2] Kajander-Unkuri S. Nurse competence of graduating nurse students. Turku: Faculty of medicine, Department of nursing science, Turun yliopisto, University of Turku. 2015; Thesis for doctoral degree.

[3] Embo M, Driessen EW, Valcke M, et al. Integrating learning assessment and supervision in a competency framework for clinical workplace education. Nurse Education Today. 2015; 35(2): 341-346.

[4] Stuart CC. Assessment, supervision and support in clinical practice: a guide for nurses, midwives and other health professionals. 2007; (2. ed.) Edinburgh: Elsevier Churchill Livingstone.

[5] Helminen K, Tossavainen K. Turunen H. Assessing clinical practice of student nurses: Views of teachers, mentors and students. Nurse Education Today. 2014; 34(8): 1161-6. PMid:24874072 https://doi.org/10.1016/j.nedt.2014.04.007

[6] Ulfvarson J, Oxelmark L. Developing an assessment tool for intended learning outcomes in clinical practice for nursing students.
Nursing Education Today. 2012; 32(6): 703-8. PMid:22051102 https://doi.org/10.1016/j.nedt.2011.09.010

[7] Eulau L, Sundman C, Scheja M, et al. Assessing Students' Learning in Student-dedicated Treatment Rooms during Clinical Nursing Education. Nursing and Health. 2015; 3(1): 22-29. https : //doi.org/10.13189/nh.2015.030104

[8] Burke E, Kelly M, Byrne E, et al. Preceptors' experiences of using a competence assessment tool to assess undergraduate nursing students. Nurse Education in Practice. 2016; 17: 8-14. PMid:27038082 https ://doi.org/10.1016/j.nepr.2016.01.004

[9] Nilsson J, Johansson E, Egmar AC, et al. Development and validation of a new tool measuring nurses self-reported professional competence - The nurse professional competence (NPC) Scale. Nurse Education Today. 2014; 34(4): 574-580. PMid:23938092 https://doi.org/10.1016/j.nedt.2013.07.016

[10] Licen S, Plazar N. Identification of nursing competency assessment tools as possibility of their use in nursing education in Slovenia A systematic literature review. Nurse Education Today. 2015; 35(4): 602-608.

Published by Sciedu Press 
[11] Wilkinson J. A practical guide to assessing nursing students in clinical practice. British Journal of Nursing. 1999; (4): 218-22.

[12] Ford K, Courtney-Pratt H, Marlow A, et al. Quality clinical placements: The perspectives of undergraduate nursing students and their supervisor nurses. Nurse Education Today. 2016; 37: 97-102.

[13] Anema MG, Mc Coy J. Competency-Based Nursing Education: Guide to Achieving Outstanding Learner Outcomes. E-book. 2010.

[14] Cadorin L, Bagnasco A, Tolotti A, et al. Instruments for measuring meaningful learning in healthcare students: a systematic psychometric review. Journal of Advanced Nursing. 2016; 72(9): 1972-1990.

[15] Wu XV, Wang W, Pua LH, et al. Undergraduate nursing students' perspectives on clinical assessment at transition to practice. Contemporay Nurse. 2016.

[16] Sandelowski M. Combining Qualitative and Quantitative Sampling, Data Collection, and Analysis Techniques in MixedMethod Studies. Research in Nursing \& Health. 2000; 23: 246-255. https://doi .org/10.1002/1098-240X(200006) 23: 3<246: : AID-NUR9>3.0.CO;2-H

[17] Mezirow, J. An overview on transformative learning. In Contemporary Theories of Learning. Edited by Illeris K. London: Routledge. 2009; 90-105.

[18] Stenberg M, Carlson E. Swedish student nurses' perception of peer learning as an educational model during clinical practice in a hospital setting - an evaluation study. BMC Nursing. 2015.

[19] Löfmark A, Mårtensson G. Validation of the tool Assessment of Clinical Education (AssCE): a study using Delphi method and clinical experts. Nurse Education Today. 2017; 50: 82-86. PMid:28033551 https://doi.org/10.1016/j.nedt.2016.12.009

[20] Graneheim UH, Lundman B. Qualitative content analysis in nursing research: concepts, procedures and measures to achieve trustworthiness. Nursing Education Today. 2004; 24(2): 105-112. PMid:14769454 https://doi.org/10.1016/j.nedt.2003.10 .001

[21] Hsieh HF, Shannon SE. Three approaches to qualitative content analysis. Qualitative Health Research. 2005; 15(9): 1277-1288. PMid:16204405 https://doi.org/10.1177/10497323052766 87

[22] Campbell DT, Cecil JS. Protection of the Rights and Interests of Human Subjects in the Areas of Program Evaluation, Social Experimentation, Social Indicators, Survey Research, Secondary Analysis of Data from Administrative Records. In Appendix to The Belmont Report, 12-1-12-23. Washington, D.C. 1979. Department of Health, Education, and Welfare (DHEW).

[23] Hunt LA, McGee P, Gutteridge R, et al. Assessment of student nurses in practice: A comparison of theoretical and practical assessment results in England. Nurse Education Today. 2012; 32: 351-355.
PMid:21640448 https://doi.org/10.1016/j.nedt. 2011.05 .010

[24] Helminen K, Coco K, Johnson M, et al. Summative assessment of clinical practice of student nurses: A review of the literature. International Journal of Nursing Studies. 2016; 53: 308-319.

[25] Elliot C. Identifying and managing underperformance in nursing students. British Journal of Nursing. 2016; 25(5): 2505. PMid:26972997 https ://doi.org/10.12968/bjon. 2016.2 5.5 .250

[26] Fan JY, Wang YH, Chao LF, et al. Performance evaluation of nursing students following competency-based education. Nursing Education Today. 2015; 35(1): 97-103. PMid:25064264 https: //doi.org/10.1016/j.nedt.2014.07.002

[27] Pijl-Zieber M, Barton S, Konkin J, et al. Competence and competency-based nursing education: finding our way through the issues. Nurse Education Today. 2014; 34: 676-678.

[28] Serçekuş P, Başkale H. Nursing students' perceptions about clinical learning environment in Turkey. Nurse Education in Practice. 2015.

[29] Manninen K. Experiencing authenticity: the core of student learning in clinical practice. Doctoral thesis Stockholm. Karolinska Institutet, Stockholm. 2014. Available from: http://hdl.handle.net/106 $16 / 41988$

[30] Andrews GJ, Brodie DA, Andrews JP, et al. Professional roles and communications in clinical placements: A qualitative study of nursing students' perceptions and some models for practice. International Journal of Nursing Studies. 2006; 43: 861-874. PMid:16380124 https://doi.org/10.1016/j.ijnurstu.2005.11.008

[31] Hauer KE, Ten Cate O, Boscardin Irby DM, et al. Understanding trust as an essential element of trainee supervision and learning in the workplace. Advanced in Health Science Education. 2014; 19: 435.

[32] Statistics Sweden. Higher Education. Students and graduates at first and second cycle studies 2014/15. UF20 - Higher education. Undergraduate education. ISSN 1654-3424.

[33] Porter S. Validity, trustworthiness and rigour: reasserting realism in qualitative research. Journal of Advanced Nursing. 2007; 60(1): 7986. PMid:17824942 https://doi .org/10.1111/j.1365-2648. $2007.04360 . \mathrm{x}$

[34] Rolfe G. Validity, trustworthiness and rigour: quality and the idea of qualitative research. Journal of Advanced Nursing. 2006; 53(3): 304-10. PMid:16441535 https : //doi.org/10.1111/j.1365-2 $648.2006 .03727 . \mathrm{x}$

[35] Sandelowski M. Focus on research methods: Whatever happened to qualitative descriptions? Research in Nursing and Health. 2000; 23(4): 334-340. https ://doi.org/10.1002/1098-240X (2000 08) $23: 4<334::$ AID-NUR9>3.0.CO;2-G 